\title{
The epithelial sodium channel mediates the directionality of galvanotaxis in human keratinocytes
}

\author{
Hsin-ya Yang ${ }^{1}$, Roch-Philippe Charles ${ }^{2}$, Edith Hummler ${ }^{2}$, Deborah L. Baines ${ }^{3}$ and R. Rivkah Isseroff ${ }^{1, *}$ \\ ${ }^{1}$ Department of Dermatology, University of California, Davis, CA 95616, USA \\ 2Département de Pharmacologie et de Toxicologie, Université de Lausanne, 1005 Lausanne, Switzerland \\ ${ }^{3}$ Pharmacology and Cell Physiology Research Group, Division of Biomedical Sciences, St George's, University of London, London, UK \\ *Author for correspondence (rrisseroff@ucdavis.edu)
}

Accepted 18 February 2013

Journal of Cell Science 126, 1942-1951

(C) 2013. Published by The Company of Biologists Ltd

doi: $10.1242 / j c s .113225$

\section{Summary}

Cellular directional migration in an electric field (galvanotaxis) is one of the mechanisms guiding cell movement in embryogenesis and in skin epidermal repair. The epithelial sodium channel $(\mathrm{ENaC})$, in addition to its function of regulating sodium transport in kidney, has recently been found to modulate cell locomotory speed. Here we tested whether $\mathrm{ENaC}$ has an additional function of mediating the directional migration of galvanotaxis in keratinocytes. Genetic depletion of $\mathrm{ENaC}$ completely blocks only galvanotaxis and does not decrease migration speed. Overexpression of $\mathrm{ENaC}$ is sufficient to drive galvanotaxis in otherwise unresponsive cells. Pharmacologic blockade or maintenance of the open state of $\mathrm{ENaC}$ also decreases or increases, respectively, galvanotaxis, suggesting that the channel open state is responsible for the response. Stable lamellipodial extensions formed at the cathodal sides of wild-type cells at the start of galvanotaxis; these were absent in the $\mathrm{ENaC}$ knockout keratinocytes, suggesting that $\mathrm{ENaC}$ mediates galvanotaxis by generating stable lamellipodia that steer cell migration. We provide evidence that $\mathrm{ENaC}$ is required for directional migration of keratinocytes in an electric field, supporting a role for $\mathrm{ENaC}$ in skin wound healing.

Key words: Keratinocyte, Directional migration, ENaC, Lamellipodia

\section{Introduction}

Skin functions as an important protective organ, shielding the body from infections, and fluid or thermal loss. The presence of a transepithelial electrical potential is an interesting physiological feature of healthy intact skin, observed to be present in human skin as early as the 19th century (reviewed by McCaig et al., 2005). A $20-65 \mathrm{mV}$ potential difference is measured between the surface of the epithelium and dermis (Barker et al., 1982; Foulds and Barker, 1983) with the inside positive relative to the surface. The non-conductive stratum corneum and polar distribution of higher concentrations of cations including calcium, potassium and sodium within the upper level of the epidermis (Denda et al., 2000; Leinonen et al., 2009) are hypothesized to maintain this transepithelial potential.

When the skin is wounded, the transepithelial potential collapses to zero at the cut site, while the persistence of the higher potential within the adjacent intact epidermis at the wound edge generates a weak electric field (EF) which then drives current flow toward the center of the wound (the cathode) (Barker et al., 1982; Ojingwa and Isseroff, 2003; Reid et al., 2007; Nuccitelli et al., 2008). The wound EF can be measured within several millimeters from the wound edge in newt (Borgens et al., 1977), guinea pig (Barker et al., 1982), mouse (Reid et al., 2007; Nuccitelli et al., 2008) and human (Mukerjee et al., 2006; Reid et al., 2007) skin and cornea, and ranges from $90 \mathrm{mV} / \mathrm{mm}$ in human to $180 \mathrm{mV} / \mathrm{mm}$ in rodent skin wounds. The EF persists until the wound is fully resurfaced with new epithelium (Borgens et al., 1977; Nuccitelli et al., 2008), and thus has been proposed to be an important component of the wound repair process.
The directional migration of cultured epithelial or corneal keratinocytes toward the cathode in an applied EF has been well documented and provides a strong mechanistic link for the purported role of the endogenous wound EF in healing. When exposed to an EF of the magnitude of those found within wounds $(100 \mathrm{mV} / \mathrm{mm})$, cultured human skin keratinocytes migrate directionally toward the cathode (the negative pole) within 15 minutes of EF exposure (Nishimura et al., 1996). As an early and persistent feature of the wound, the wound EF provides a directional signal to guide migrating epithelial cells toward the wound center (Nishimura et al., 1996; Sheridan et al., 1996; Zhao et al., 1996; Zhao et al., 1997; Fang et al., 1998; Fang et al., 1999; Zhao et al., 1999; Farboud et al., 2000). How the wound EF mediates directional migration of epithelial cells is, as yet, not fully understood, and that is what this investigation addressed.

The epithelial sodium channel, ENaC, is a non-voltage-gated, amiloride-sensitive sodium channel highly expressed in kidney, lung, and distal colon. $\mathrm{ENaC}$ is a heterotrimeric channel comprising three homologous subunits, $\alpha-, \beta$-, and $\gamma-$, each of which shares about $35 \%$ amino acid sequence homology (McDonald et al., 1994; Voilley et al., 1994; McDonald et al., 1995; Voilley et al., 1995). The alpha subunit $(\alpha \mathrm{ENaC})$ is the major pore forming subunit, and beta- and gamma- subunits mediate degradation of the channel (Benos et al., 1996; Awayda et al., 1997; Garty and Palmer, 1997; Alvarez de la Rosa et al., 2000). The major function of $\mathrm{ENaC}$ is to mediate trans-epithelial sodium transport and water balance in polarized epithelia, yet $\mathrm{ENaC}$ is also expressed in non-sodium absorbing epithelia, such as the epidermis. $\alpha \mathrm{ENaC}$ mRNA and protein are detected in 
human primary keratinocytes (Brouard et al., 1999) and murine epithelium (Mauro et al., 2002). Although the genetic ablation of the $\alpha \mathrm{ENaC}$ gene in mice results in a postnatal lethal phenotype due to an inability to clear lung fluids (Hummler et al., 1996), the role of this channel in skin epithelial biology is not yet elucidated. $\alpha \mathrm{ENaC}$ knockout mice do have abnormal lipid composition in their stratum corneum (Mauro et al., 2002; Charles et al., 2008), but these animals do not survive long enough to perform in vivo skin investigations. In humans, loss-offunction mutations of $\alpha \mathrm{ENaC}$ genes cause a rare autosomal, recessive disease: pseudohypoaldosteronism type 1 (Chang et al., 1996; Strautnieks et al., 1996), resulting in salt loss, hyperkalemia and metabolic acidosis in newborns. Although cutaneous lesions have been described in case reports of the pseudohypoaldosteronism type 1 patients, these lesions are possibly related to the high concentration of salt in sweat glands (Urbatsch and Paller, 2002; Martín et al., 2005).

Several recent studies suggest that $\alpha \mathrm{ENaC}$ is involved in cell migration in vitro. Inhibition of $\alpha \mathrm{ENaC}$ activity in bovine corneal endothelial (BCE), rat aortic vascular smooth muscle cells, and human BeWo cells decreases the rate of scratch wound closure compared to the control (Chifflet et al., 2005; Grifoni, et al., 2006; Grifoni, et al., 2008; Del Mónaco et al., 2009). Additionally, an ENaC-dependent $\mathrm{Na}^{+}$-influx at the wound edge of BCE cells was observed upon the generation of the scratch wound (Chifflet et al., 2005), suggesting that opening of $\mathrm{ENaC}$ channels may be the initial step in migration and wound closure for these cells. However, little is known about how, or if, $\alpha \mathrm{ENaC}$ mediates cell motility or directional migration such as galvanotaxis.

In the current study, we examined the hypotheses that $\mathrm{ENaC}$ mediates the directional migratory galvanotaxis response in skinderived keratinocytes, thus contributing to cutaneous wound repair. We found that $\mathrm{ENaC}$ expression is required for the galvanotaxis directional response: knocking down $\mathrm{ENaC}$ or blocking $\mathrm{ENaC}$ channels does not alter overall cell motility yet remarkably inhibits the directional response of keratinocyte galvanotaxis. Overexpressing $\mathrm{ENaC}$ could drive galvanotaxis in cells that are ordinarily non-responsive to an applied EF. Additionally, preferential lamellipodial protrusion at the cathodal side of the cell is dependent on $\mathrm{ENaC}$ expression, and in $\mathrm{ENaC}$-deficient cells, no cathodally dominant lamellipodia are established. Our findings suggest a novel function for $\mathrm{ENaC}$ in mediating the directional migration of keratinocyte, by stabilizing protrusions at the cathodal side during galvanotaxis. These findings help explain the elusive mechanism of cellular directional responses to physiological electrical fields.

\section{Results \\ ENaC-depleted keratinocytes lose directionally in galvanotaxis}

To investigate the role for $\mathrm{ENaC}$ in keratinocyte galvanotaxis, we examined the directionality of the migratory response in an EF of physiologic magnitude in murine and human keratinocytes that had been genetically depleted of $\alpha \mathrm{ENaC}$. The morphology of $\alpha \mathrm{ENaC}$ knockout mouse epithelial keratinocytes $(\alpha \mathrm{ENaC}-\mathrm{KO}-$ MEK) $(-/-)$ is similar to that of the wild-type MEK $(+/+)$ (Fig. 1A; supplementary material Movies 1, 2) (Hummler et al., 1996) ( $\alpha \mathrm{ENaC}$ depletion in the knockout MEK is shown in supplementary material Fig. S1A). Although $\alpha$ ENaC-KO-MEK migrated significantly faster than the wild-type MEK
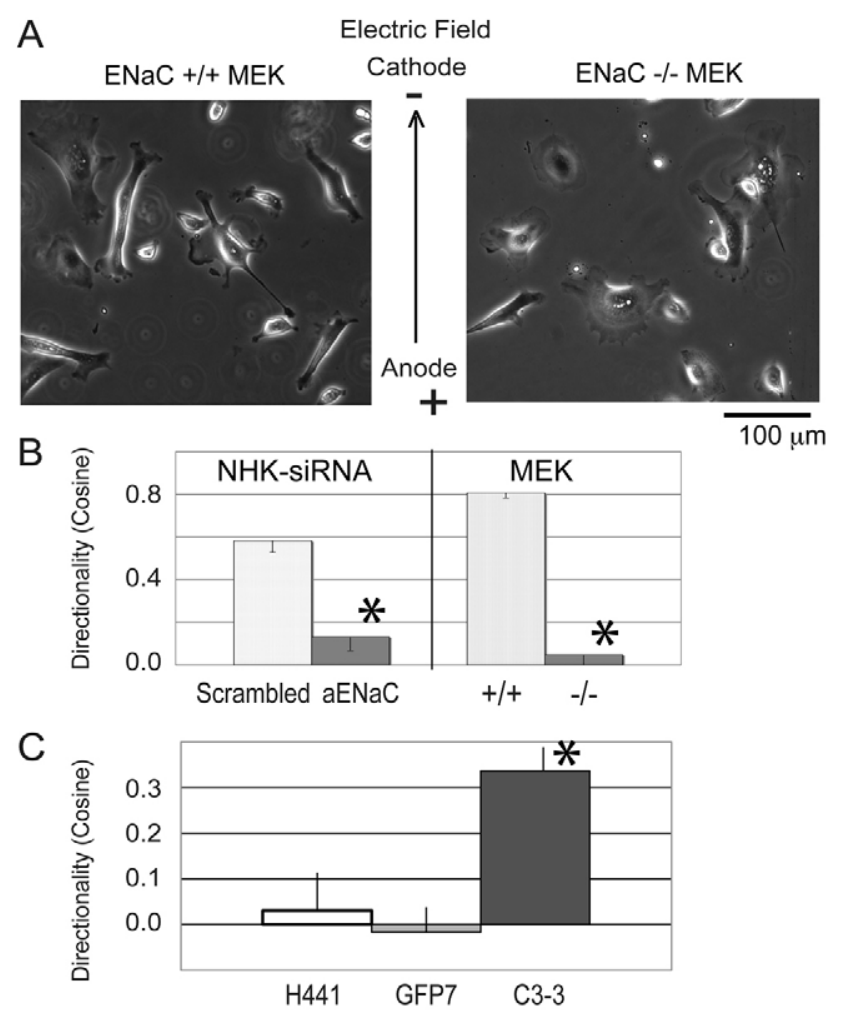

Fig. 1. Depletion of ENaC inhibits galvanotaxis of keratinocytes, but overexpression of EGFP-ENaC promotes galvanotaxis. (A) Representative images from the wild-type MEK and the ENaC-depleted MEK in EF (also supplementary material Movies 1-4). (B) The migration speeds of keratinocytes are between 1 and $2 \mu \mathrm{m} /$ minute. Left: The directionality decreases by $80 \%$ in human NHK treated with $\alpha$ ENaC siRNA (120 cells tracked). Right: $\alpha E N a C-K O-M E K$ also lose $94 \%$ of their directionality in the EF (+/+ wild type, 104 cells tracked; -/- $\alpha$ ENaC knockout, 93 cells tracked). Although $\alpha E N a C-K O-M E K$ migrate faster than wild-type $\mathrm{MEK}$, the migration speed of the ENaC siRNA-treated $\mathrm{NHK}$ is similar to that of scrambled siRNA-treated NHK $(1.2 \pm 0.46 \mu \mathrm{m} /$ minute versus $1.1 \pm 0.47 \mu \mathrm{m} /$ minute; not significantly different; migration speed not shown).

(C) Galvanotaxis of parental H441 cell lines H441 (80 cells tracked), GFP7 (EGFP expressing H441, 165 cells tracked) and $\alpha \mathrm{C} 3-3-\mathrm{GFP}$ (EGFP- $\alpha$ ENaC expressing H441, 165 cells tracked) were examined. The H441 and GFP7 lines that express very low levels of endogenous $\alpha \mathrm{ENaC}$ do not respond with directional migration to the EF (cosine is close to zero). However,

introduction of a functional $\alpha \mathrm{ENaC}$ channel (in the $\alpha \mathrm{C} 3-3-\mathrm{GFP}$ ) significantly increases the cathodal directionality (cosine) of the cells. ${ }^{*} P<0.05$.

$(0.86 \pm 0.04 \mu \mathrm{m} /$ minute versus $0.73 \pm 0.03 \mu \mathrm{m} /$ minute for wildtype keratinocytes, $P<0.05$ ), the directional response was essentially absent (decreased by $94 \%, P<0.05$ ) in the $\alpha \mathrm{ENaC}$ KO-MEK, with resultant random, rather than cathodally directed migration in the EF (Fig. 1B, right). Similar results were obtained from siRNA knockdown of $\alpha \mathrm{ENaC}$ in human keratinocytes. The total $\alpha \mathrm{ENaC}$ expressed in NHK is decreased by $50 \%$ after 72 hours of siRNA treatment (supplementary material Fig. S1B), at which time the migratory response to the EF was examined (Fig. 1B, left; supplementary material Movies 3, 4). As in the $\alpha \mathrm{ENaC}-\mathrm{KO}-\mathrm{MEK}, \alpha \mathrm{ENaC}$ siRNA-treated NHK demonstrate a significant decrease in cathodally-directed galvanotaxis (Fig. 1B, left) compared to the control cells, indicating the loss of a directional migratory response to the applied EF. 


\section{Overexpression of active $\alpha \mathrm{ENaC}$ promotes galvanotaxis}

To further examine whether $\alpha \mathrm{ENaC}$ is sufficient to drive the cellular galvanotaxis response, we tested galvanotaxis in cells overexpressing $\alpha \mathrm{ENaC}$. A human lung epithelial cell H441 line (parental), its EGFP- tagged $\alpha \mathrm{ENaC}$ overexpressing cell line derivative ( $\alpha$ C3-3-GFP) as well as a control EGFP expressing cell line (GFP7) were examined for their directional migration in response to an applied EF. The $\alpha \mathrm{C} 3$-3-EGFP ENaC overexpressing line demonstrates increased levels of total $\alpha \mathrm{ENaC}$ relative to the parental cell line $\mathrm{H} 441$ or the control EGFP expressing line (the endogenous and the GFP- $\alpha \mathrm{ENaC}$, supplementary material Fig. S1C) (Woollhead and Baines, 2006). All three cell lines H441, GFP7 and $\alpha$ C3-3-GFP migrated with similar speeds of $0.55 \pm 0.04,0.57 \pm 0.02$, and $0.60 \pm 0.02 \mu \mathrm{m} /$ minute (insignificantly different) in the EF. However, the cosine values for the H441 and GFP7 lines are close to zero, indicating no directedness of migration (Fig. 1C), demonstrating that these cells migrated randomly without a directional response to the EF. On the other hand, the $\alpha \mathrm{C} 3-3$-GFP cells overexpressing active $\alpha \mathrm{ENaC}$ showed a significant increase in cosine value (cosine $=0.35$, $P<0.05)$ compared to control GFP7 and the parental line $($ cosine $=0)$, indicating a directional cathodal response to the EF.

\section{The open state of ENaC is involved in NHK directionality in galvanotaxis}

In addition to genetic manipulations of levels of expression of $\alpha \mathrm{ENaC}$, we investigated whether $\mathrm{ENaC}$ in the open state is required to drive galvanotaxis, using pharmacologic modulation of its channel activity. Previously we showed that amiloride, a blocker of the open state of the ENaC channel at a low concentration of $10 \mu \mathrm{M}$ has no effect on galvanotaxis (Trollinger et al., 2002); therefore, we treated the cells with a more potent and $\mathrm{ENaC}$-specific amiloride analog, phenamil $\left(\mathrm{IC}_{50}\right.$ is $284 \mathrm{nM}$ for amiloride and $75 \mathrm{nM}$ for phenamil tested on human bronchial epithelial cells; Hirsh et al., 2004) and monitored the NHK migration in the EF. Migration speeds of control and $20 \mu \mathrm{M}$ phenamil-treated NHK are similar at $1.02 \pm 0.43 \mu \mathrm{m} /$ minute. While control cells demonstrate robust cathodal directional migration, in the presence of phenamil, the cosine value of NHK migrating toward the cathode is decreased by $30 \%$ (Fig. 2A, $P<0.05$ ), suggesting that the sodium influx via $\mathrm{ENaC}$ channel is involved in, but is not the major signal for the NHK directional migration in an electric field.

\section{The inhibitory peptide derived from $\alpha \mathrm{ENaC}$ cleavage impairs NHK galvanotaxis}

Activation of the ENaC channel by proteases releases a short self-inhibitory sequence from the mouse $\alpha \mathrm{ENaC}$ of amino acids 182-190, LPHPLQRL (Carattino et al., 2006; Carattino et al., 2008). The cleaved $\mathrm{ENaC}$ channel is constitutively active and stays in the open state; treating mouse cortical collecting duct cells and human airway epithelial cells with synthetic LPHPLQRL peptide blocks the opening of ENaC (Carattino et al., 2006; Carattino et al., 2008). We used this inhibitory peptide to further confirm the role of open ENaC channels in galvanotaxis. Addition of the peptide to the cells did not alter migration speed, since NHK cultured with either the inhibitory peptide or the scrambled control peptide migrated at the same speed. Similar to the phenamil inhibition, with the pre-treatment of $20 \mu \mathrm{M} \alpha \mathrm{ENaC}$ inhibitory peptide, the net cosine value of $\mathrm{NHK}$ galvanotaxis decreased by $30 \%$ (Fig. $2 \mathrm{~B}, P<0.05$ ) from control

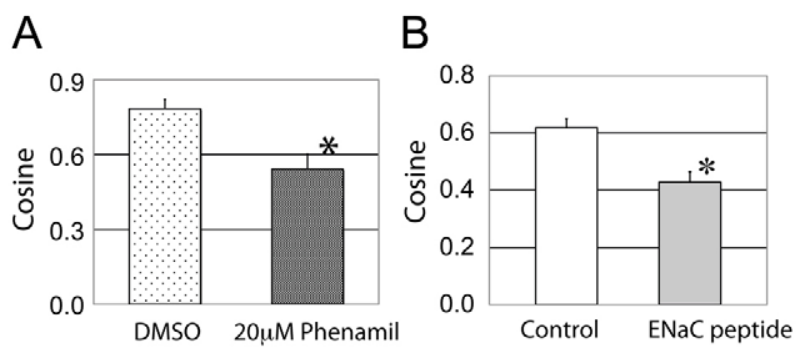

C

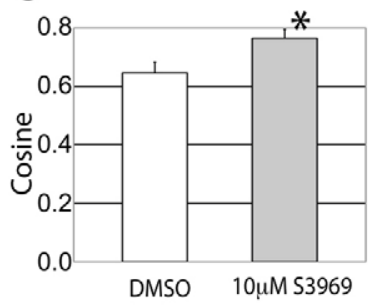

D

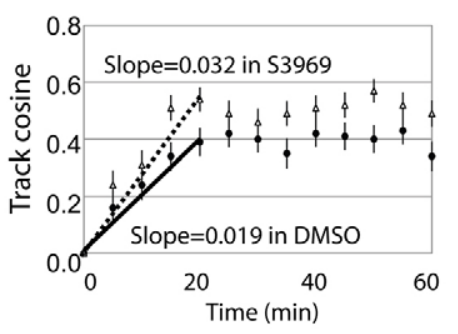

Fig. 2. Blocking the open state of ENaC prevents keratinocyte galvanotaxis, whereas increasing the open state of the $\mathrm{ENaC}$ channel by S3969 increases galvanotaxis. (A) In the cells pre-treated with $20 \mu \mathrm{M}$ phenamil, the directionality of NHK in galvanotaxis is inhibited by $30 \%$ (110 cells tracked in each group). (B) NHK treated with a control peptide or $20 \mu \mathrm{M}$ $\mathrm{ENaC}$ inhibitory peptide migrate at similar rates (migration speed not shown), but the cathodal directionality is decreased by $30 \%$ in the cells treated with the $\alpha \mathrm{ENaC}$ derived peptide $(235$ cells tracked in control and 275 cells tracked in the treatment with the inhibitory peptide). Therefore, the open state of $\alpha \mathrm{ENaC}$ channel is required for NHK galvanotaxis. (C) S3969 was added to NHK 30 minutes prior to the EF exposure. The migration speed was not affected (migration speed not shown), but the directionality (net cosine) of cells increased by 17\%. (D) S3969 treatment (open triangles) also increased the slope of the track cosine compared to the DMSO control group (solid circles) in the initial 20 minutes of EF exposure, which suggests that opening the $\mathrm{ENaC}$ channel promotes a more persistent, directional migration of NHK in the EF (167 cells tracked). $* P<0.05$.

values. These results provide additional support to the notion that the $\mathrm{ENaC}$ channel in open state is required for galvanotaxis.

\section{Opening ENaC channels promotes NHK directional migration in an EF}

On the other hand, if $\mathrm{ENaC}$ in the open state is required for galvanotaxis, it is reasonable to propose that constitutively active $\mathrm{ENaC}$ should promote $\mathrm{NHK}$ directional migration. An ENaC activating agent, S3969, increases the open probability of the channel by activating the beta subunit (Lu et al., 2008). When normal human keratinocytes are pre-treated with S3969 prior to the EF exposure, they demonstrate a $17 \%$ increase in the net cosine value from 0.65 to $0.76(P<0.05)$ at the end of the 60 minutes galvanotaxis assay (Fig. 2C) compared to the control, while maintaining similar migratory speeds. Opening ENaC by S3969 also increases the slope of the track cosine in the first 20 minutes during galvanotaxis (0.019 in DMSO versus 0.027 in S3969, Fig. 2D), indicating that the S3969 treated keratinocytes migrate on a more persistent, directional route toward cathode in the EF than control cells. These results indicate that $\mathrm{ENaC}$ channel at the open state could promote galvanotaxis.

Since the accumulated data support a role for $\mathrm{ENaC}$ in keratinocyte galvanotaxis in vitro, and skin wounds generate an 
EF of the magnitude used in these studies, we examined how wound healing is affected by the $\mathrm{ENaC}$ inhibitor phenamil using an organotypic, ex vivo human wound assay, in which the early stage of wound re-epithelialization, dependent on keratinocyte migration, can be quantitated (Kratz, 1998; Lu and Rollman, 2004). Wound re-epithelialization of control wounds was 90 $95 \%$ complete after 7 days of ex vivo cultivation and a single layer of NHK covered the original wound area (supplementary material Fig. S2A,B). However, in the presence of $10 \mu \mathrm{M}$ phenamil, the re-epithelialization is blocked by $70 \%$ compared to the control solvent DMSO treatment at day 7 (87.8\% in DMSO versus $28.2 \%$ in phenamil, $P<0.05$, supplementary material Fig. S2B-D) and the NHK migrated only minimally into wound. The results suggest that inhibiting $\mathrm{ENaC}$ activity by phenamil inhibited keratinocyte migration and re-epithelialization of the wound in the first 4 days of healing, and at later times, impaired viability may have contributed to the decrease in wound reepithelialization (PCNA staining and extracellular lactate dehydrogenase activity in supplementary material Fig. S3).

\section{NHE1 is not involved in keratinocyte galvanotaxis}

Another sodium transporter, NHE-1, present in cultured NHK and skin epithelium mediates the $\mathrm{pH}$ homeostasis and the epithelial barrier function (Hachem et al., 2005). It is also required for establishment of fibroblast polarity during directional migration (Denker et al., 2000; Frantz et al., 2007). Amiloride or phenamil, inhibitors of $\mathrm{ENaC}$ activity and galvanotaxis, can also inhibit NHE-1 at high concentration (Frelin et al., 1988) and theoretically could impair galvanotaxis by this mechanism. Therefore, we examined whether NHE1 is involved in galvanotaxis by using the NHE1-specific inhibitor cariporide to treat keratinocytes and also by examining galvanotaxis of PS120 fibroblast strains expressing wild-type NHE1 (PSN) or the dead NHE1 transporter (E266I, a mutant NHE1 containing an isoleucine substitution to glutamate 266, Denker et al., 2000).

NHK migration speeds were not inhibited in a high concentration of $50 \mu \mathrm{M}$ cariporide (cariporide $K_{\mathrm{I}} \mathrm{S}=0.05 \mu \mathrm{M}$ for NHE-1, Scholz et al., 1995) $(10 \mu \mathrm{M}$ cariporide inhibits a melanoma cell line MV3 migration, Stock et al., 2005) (Fig. 3A, left), and the directionality in response to an applied EF was also not altered (Fig. 3A, right). Similar results were observed when we compared the fibroblasts expressing the defective NHE1 (E266I) to wild-type NHE1 (PSN). Galvanotaxis of the fibroblasts expressing either wild-type NHE1 or the deficient NHE1 show the same degree of directionality in the EF (Fig. 3B, right), suggesting that unlike $\mathrm{ENaC}$, the sodium transporter NHE1 is not required for galvanotaxis.

\section{ENaC translocates to the leading edge of NHK after 60 minutes exposure of the EF}

One mechanism by which EF may guide directional migration is to induce asymmetric relocalization of pro-migratory signals to the leading edge of the cell, as has been shown for the EGF receptor (Fang et al., 1999; Zhao et al., 1999) and PI(3)K gamma (Zhao et al., 2006). To study if ENaC translocates to the cathodal edge of the cell during galvanotaxis, $\alpha \mathrm{ENaC}$ was immunolocalized in both NHK and MEK at different time points after exposure to the $\mathrm{EF}$, using antibodies that detect all forms of $\alpha \mathrm{ENaC}$ : the fulllength $80-85 \mathrm{kDa}$ and the cleaved, active $60-65 \mathrm{kDa}$ (Fig. 4B) (Carattino et al., 2006; Carattino et al., 2008). At time zero, $\alpha \mathrm{ENaC}$ was randomly located at the cell periphery and in perinuclear areas
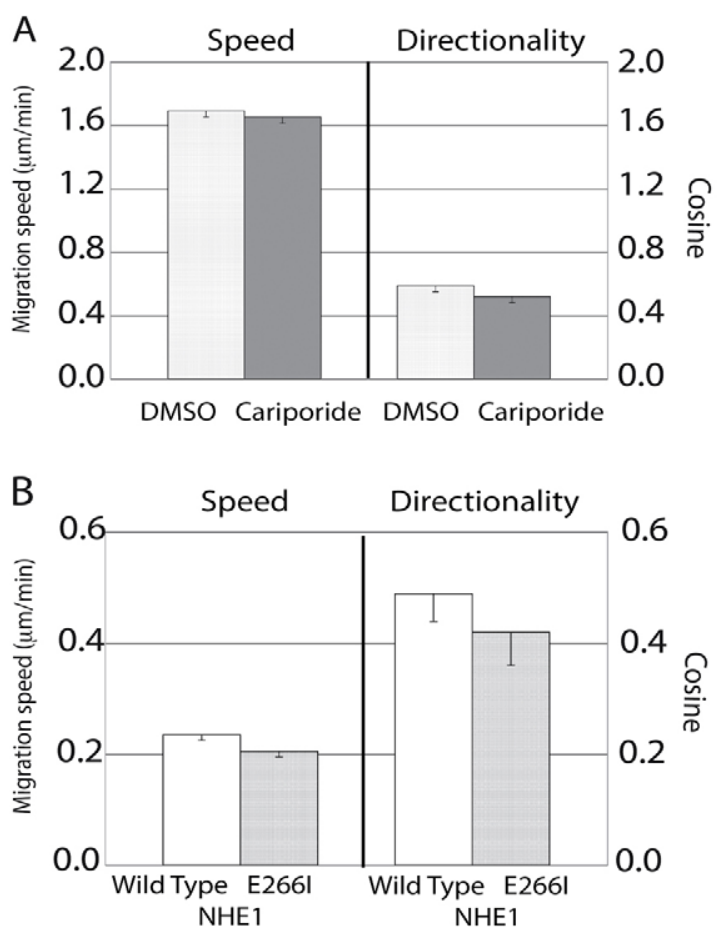

Fig. 3. NHE1 is not required for keratinocyte galvanotaxis. (A) NHK galvanotaxis was examined in the presence of DMSO or $50 \mu \mathrm{M}$ cariporide in DMSO. The NHK migration speed (left) and directionality (right) were not inhibited in DMSO or in $50 \mu \mathrm{M}$ cariporide (180 cells tracked in each group). (B) Fibroblasts expressing wild-type NHE1 (PSN) or the E266I-NHE1 were exposed to the EF to examine galvanotaxis. Both fibroblast lines

demonstrated statistically equal migration speeds and directionality ( 110 cells tracked in each group), further supporting the conclusion that NHE1 is not required for keratinocyte galvanotaxis. Note the difference in scale on the $y$-axis in $\mathrm{A}$ and $\mathrm{B}$.

(Fig. 4A). When keratinocytes are exposed to the EF, $\alpha \mathrm{ENaC}$ is not detected at the leading edge of NHK until 60 minutes after exposure (Fig. 4A,C). At this time, the staining intensity is $14 \%$ higher at the cathodal side than at the anodal side in NHK (Fig. 4C, $P<0.05)$. Since the directional migratory response to the applied $\mathrm{EF}$ is detected as early as 15 minutes after exposure (Nishimura et al., 1996), the temporal lag in relocalization of $\mathrm{ENaC}$ to the lamellipodium suggests that polarization of $\mathrm{ENaC}$ to the leading edge of the lamellipodium may not mediate the galvanotaxis response.

\section{ENaC stabilizes lamellipodial protrusion at the cathodal side during galvanotaxis}

The role of lamellipodial dynamics in mediating the directional migratory response in galvanotaxis has not yet been investigated. However, in the directional response in chemotaxis, analysis of lamellipodial and pseudopodial dynamics has provided two models for directional cell steering. A chemoattractant could induce (1) de novo formation of cell protrusions toward the gradient or (2) the differentiation of existing protrusions and stabilization of the ones facing the gradient (Andrew and Insall, 2007).

Similar to chemotaxis, keratinocytes could orient their cell bodies during galvanotaxis using lamellipodial steering. NHK in the control galvanotaxis groups, were not always polarized to the 
A

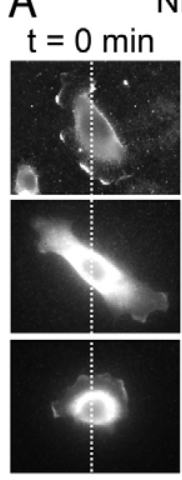

$-20 \mu \mathrm{m}$

B
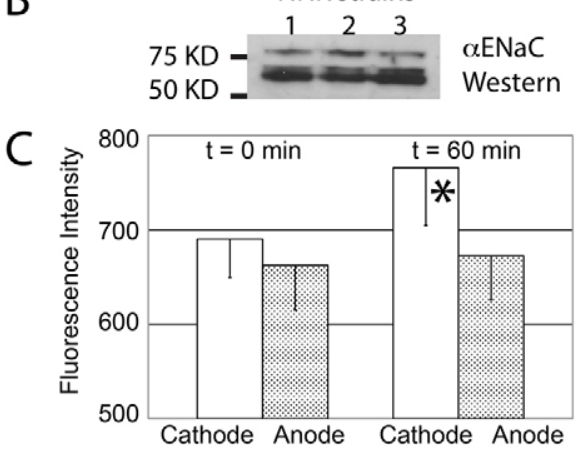

Fig. 4. $\alpha \mathrm{ENaC}$ polarizes to the cathodal side of keratinocytes after 60 minutes of galvanotaxis. (A) Immunostaining shows that $\alpha \mathrm{ENaC}$ is distributed randomly at cell periphery of NHK and MEK before exposure to the $\mathrm{EF}$ ( 0 minutes, cathode on right of the image). After 60 minutes in the $\mathrm{EF}$, $\mathrm{ENaC}$ is concentrated at the cathodal side of cells. (B) Both uncleaved $(\sim 80$ $85 \mathrm{kDa})$ and cleaved $\alpha \mathrm{ENaC}(60-65 \mathrm{kDa})$ bands were detected with western blotting on three strains of NHKs. (C) At 0 minutes, the fluorescence intensity between the cathodal side and anodal side of keratinocytes is similar (left), but at 60 minutes, the fluorescence is increased at the cathodal side (right, ${ }^{*} P<0.05,20$ human keratinocytes analyzed in each group).

fan shape. Before EF exposure, the ratio of different cell shapes were: $34.1 \pm 10.3 \%$ for fan-shaped cells, $26.1 \pm 9.5 \%$ for bipolarshaped cells and $39.9 \pm 12.1 \%$ for other cell shapes including round cells or cells with multiple protrusions. After a 60 minutes EF exposure resulting in a cosine value of 0.58 , the ratios are $38.2 \pm 12.0 \%$ for fan-shaped, $27.4 \pm 6.3 \%$ for bipolar-shaped, and $34.1 \pm 12.3 \%$ for others. There is no significant difference between the ratios of keratinocyte cell shape types with or without $\mathrm{EF}$ exposure. This observation suggests that the $\mathrm{EF}$ may not promote de novo formation of protrusions toward the cathode, since EF exposure resulted in no change in the observed ratio of the fan-shaped, polarized keratinocytes. Therefore, we tested the second possibility, that physiologic EFs could stabilize existing cathodal-facing lamellipodia in keratinocytes resulting in gradual change of the direction of migration toward the cathode. This mechanism would result in smooth turns, and increase the cosine value slowly until the cathodally oriented lamellipodia dominate and guide the migratory response in that direction, and fit our observation of the kinetics of galvanotaxis (for example, Fig. 2D, DMSO control). To analyze whether the data fit this model, we selected polarized keratinocytes whose fan shaped lamellipodia were situated perpendicular to the axis of the $\mathrm{EF}$, and therefore half of the cell could be defined as anodal-facing and the other half as cathodal-facing (Fig. 5A). Kymographic analysis of the leading edge was performed (Fig. 5B-D) to compare the lamellipodial protrusion and retraction distances and rates while cells migrated in an applied EF.

In wild-type MEK, the protrusion distance is $50-65 \%$ further at the cathodal as compared to anodal-facing side of the cell (Fig. $5 \mathrm{~A}, 12.5 \pm 1.9 \mu \mathrm{m}$ at line 9 versus $7.8 \pm 1.4 \mu \mathrm{m}$ at line 1 ; similar results at line 8 versus line 2 , the distance panel in Fig. 5C, $P<0.05)$ and the protrusion speed of cathodal-facing lamellipodia is faster within the first 10 minutes of EF exposure than at the anodal-facing side (the speed panel in Fig. 5C, line 9 versus line 1), which results in a further extension of lamellipodia at the cathodal side. The switching frequency between protrusion and retraction is similar on both sides. However, in the $\alpha \mathrm{ENaC}$ KO keratinocytes the distances of protrusion or retraction are very similar at the distal end of the cells, preventing an asymmetric extension of the lamellipodia during application of the $\mathrm{EF}$, and thus, no directional migratory response develops. These results suggest that the cathodal lamellipodia are more stable and extend faster and further in the wild type, galvanotactically responsive keratinocytes, as compared to the cells in which $\alpha \mathrm{ENaC}$ is genetically depleted. Based on this analysis, we propose that $\alpha \mathrm{ENaC}$ in wild-type keratinocytes is required for establishing stable lamellipodia at the cathodal side during galvanotaxis and that the directional stabilization of the lamellipodia is an important mechanism to orient and steer keratinocyte migration in galvanotaxis.

A difference between the overall protrusion speed of the lamellipodia in the wild type and in the $\alpha \mathrm{ENaC}-\mathrm{KO}-\mathrm{MEK}$ was observed as well. There is an $18 \%$ significant increase of the migration speed of the $\mathrm{KO}$ cells $(0.86 \mu \mathrm{m} /$ minute in $\alpha \mathrm{ENaC}-\mathrm{KO}-$ MEK versus $0.73 \mu \mathrm{m} /$ minute in wild-type keratinocytes), and $24 \%$ and $45 \%$ increases of the protrusion and retraction distance in the $\alpha \mathrm{ENaC}-\mathrm{KO}-\mathrm{MEK}$ compared to the wild-type cells (Table 1, rows 1 and 4). The overall protrusion speed is also increased by $47 \%$, the duration of retraction increased by $17 \%$, and the switching between protrusion and retraction is more frequent in the $\alpha \mathrm{ENaC}-\mathrm{KO}-\mathrm{MEK}$ (Table 1, rows 2, 6 and 7). These results suggest that the function of $\alpha \mathrm{ENaC}$ in wild-type keratinocytes may be not only to stabilize a dominant, directionality-determining lamellipodium, but also to inhibit, rather than promote, multidirectional lamellipodial extension, and, thus in the absence of $\alpha \mathrm{ENaC}$ this control mechanism for lamellipodial outgrowth is impaired and cells move faster, but with less directionality.

\section{Discussion}

\section{Summary}

Although we have known for over a century that EFs exist within wounds, as well as during limb regeneration and embryogenesis, (Borgens et al., 1977; Burr, 1941) it is only recent work that has demonstrated that these EFs provide directional cues to guide migration of cells to accomplish tissue remodeling required for these physiologic events (Nishimura et al., 1996; Sheridan et al., 1996; Zhao et al., 1996; Zhao et al., 1997; Fang et al., 1998; Fang et al., 1999; Zhao et al., 1999; Farboud et al., 2000). While intracellular signaling mediators of the directional response have been identified, including the kinase domain of the EGF receptor, PI3K, PTEN, phosphorylated ERK, phosphorylated Src, Rac-1, and cAMP (Fang et al., 1999; Zhao et al., 2002; Pullar and Isseroff, 2005; Zhao et al., 2006; Pullar et al., 2006), the proximal 


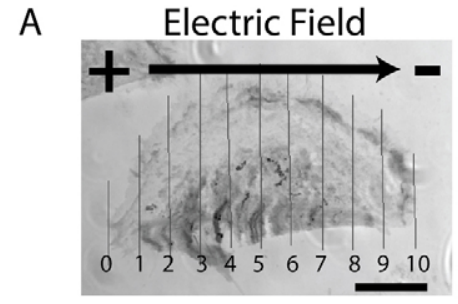

C Wild type MEK
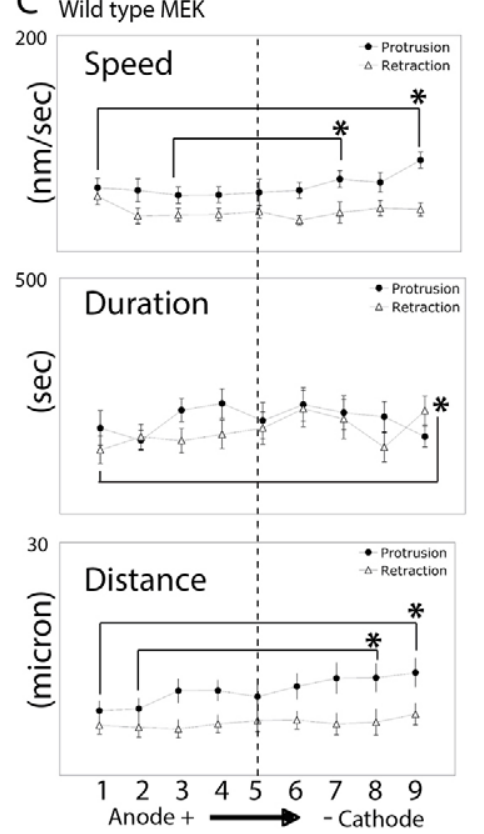

B
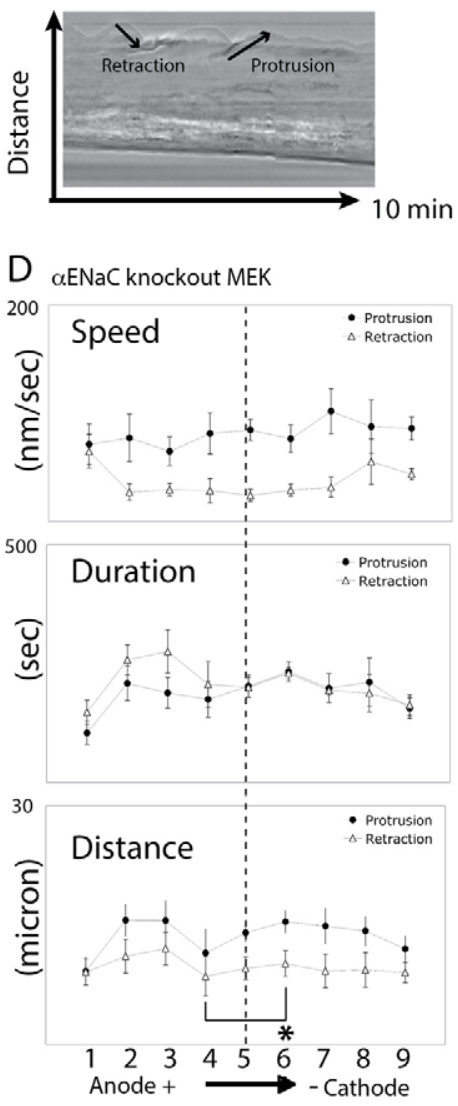

Fig. 5. ENaC is required to establish stable lamellipodia at the cathodal side of galvanotactic keratinocytes. (A) Mouse keratinocytes were exposed to the EF and filmed for 10 minutes. Fan-shaped cells were selected and a 1-pixel wide line at cell periphery was drawn every $10 \%$ of the length (lines were aligned from anode to cathode, numbered $0-10)$ across the MEK to generated kymographs. (B) The protrusion and retraction of the lamellipodia were tracked and plotted from either wildtype MEK or $\alpha \mathrm{ENaC}-\mathrm{KO}-\mathrm{MEK}$. (C,D) Wild-type MEK lamellipodia protrude faster and further at the distal cathodal side compared to the anodal side $(\mathrm{C}, n=13)$. The asymmetric protrusion is ENaC-dependent and the lamellipodia extended at a similar rate and to a similar distance at the distal sides in the $\alpha \mathrm{ENaC}$-KO-MEK ( $\mathrm{D}, n=7$ ). Quantitative data are presented in Table $1 .{ }^{*} P<0.05$ for the comparisons indicated. cellular sensor that detects the EF and initiates the signaling cascade to initiate directional migration has remained elusive. Our study demonstrates that $\mathrm{ENaC}$ plays a novel role in keratinocyte galvanotaxis and may indeed function as the proximal EF sensor, initiating directional keratinocyte migration ultimately required for wound healing. Keratinocytes in which $\alpha \mathrm{ENaC}$ is genetically depleted completely lose their ability to respond to an applied EF with directional cathodal migration, although their random locomotory speed is unaffected. $\mathrm{ENaC}$ is sufficient to establish galvanotaxis when expressed in cells that do not respond with directional migration to EFs.

Table 1. Comparison of the lamellipodial dynamics between wild-type MEK and $\alpha E N a C-K O-M E K$ within the first 10 minutes in the electric field

\begin{tabular}{|c|c|c|}
\hline Parameter & $\begin{array}{c}\text { Wild-type MEK } \\
(\text { mean } \pm \text { s.e.m. } n=13)\end{array}$ & $\begin{array}{l}\text { ENaC knockout MEK } \\
(\text { mean } \pm \text { s.e.m. } n=7)\end{array}$ \\
\hline \multicolumn{3}{|l|}{ MEK protrusion ${ }^{\S}$} \\
\hline Distance $(\mu \mathrm{m})$ & $11.0 \pm 0.6$ & $13.6 \pm 0.7 *$ \\
\hline Speed (nm/second) & $61.0 \pm 3.0$ & $81.3 \pm 6.0^{*}$ \\
\hline Duration (seconds) & $201.0 \pm 10.5$ & $186.5 \pm 11.4$ \\
\hline \multicolumn{3}{|l|}{ MEK retraction $\$$} \\
\hline Distance $(\mu \mathrm{m})$ & $6.8 \pm 0.4$ & $9.8 \pm 0.6^{*}$ \\
\hline Speed (nm/second) & $36.9 \pm 2.3$ & $37.1 \pm 3.9$ \\
\hline Duration (seconds) & $176.9 \pm 11.0$ & $207.1 \pm 11.2 *$ \\
\hline Switching frequency & $3.4 \pm 0.2$ & $4.0 \pm 0.2 *$ \\
\hline
\end{tabular}

Mechanistically, $\alpha \mathrm{ENaC}$ regulates directional migration by establishing stable lamellipodial protrusions at the cathodally facing pole of cells exposed to an EF, maintaining cellular polarity that directs the migratory response toward the cathode. Although $\mathrm{ENaC}$ has been shown to mediate migratory speed in other types of cells (Chifflet et al., 2005; Grifoni, et al., 2006; Grifoni, et al., 2008), this is the first study to show that ENaC is required for the directional cell migration in an EF and provides an important mechanistic insight as to how electrotaxis is accomplished.

\section{ENaC protein mediates galvanotaxis}

Depleting $\alpha \mathrm{ENaC}$ from keratinocytes abolished galvanotaxis, suggesting that $\alpha \mathrm{ENaC}$ or $\alpha \mathrm{ENaC}$-associated proteins mediate the directionality of the cell migration in the EF. We also tested the hypothesis that the open state of $\mathrm{ENaC}$ is required for keratinocyte galvanotaxis. Blocking the open state of $\mathrm{ENaC}$ with either phenamil or the $\mathrm{ENaC}$-derived inhibitory peptide decreases the keratinocyte galvanotaxis response. The high dosage of 10 , 20 and $40 \mu \mathrm{M}$ phenamil treatments did show a dose-dependent inhibitory response of galvanotaxis of $20-50 \%$, but the ENaC control of sodium ion transport may not be the major signal for guiding directional migratory galvanotaxis responses in keratinocytes. Another interesting observation is that opening the $\mathrm{ENaC}$ channel by pre-treatment with the $\mathrm{ENaC}$ activator S3969 increases the galvanotactic response (cosine) by $17 \%$. These results further support the observation that opening the $\mathrm{ENaC}$ channel on the cell surface enhances the directionality, but 
it is not the sole requirement to steer the keratinocyte in galvanotaxis.

In the Trollinger et al. (Trollinger et al., 2002) paper, we previously proposed that an unidentified calcium channel is required for galvanotaxis. Calcium channel blockers such as $\mathrm{Sr}^{2+}$ and $\mathrm{Gd}^{3+}$ inhibited the directionality of keratinocytes, but the localization or the timing of the activation of the calcium channel remains unclear. In the current study, we found $\mathrm{ENaC}$ also mediates galvanotaxis. There could be several pathways involved in galvanotaxis, including sensing of the electric field, determining the direction to migrate, maintaining a persistent direction of migration, and the controlling of cell adhesion and migration speed. $\mathrm{ENaC}$ appears to be important in sensing of the electric field and determining the direction of migration (see below). Calcium and the postulated calcium channel might be involved in cell adhesion and migration rate. Future studies will be required to test if a calcium channel is downstream of $\mathrm{ENaC}$ in guiding the directional response, or whether they are parallel pathways that control different cellular responses in galvanotaxis.

Although the $\mathrm{Na}^{+} / \mathrm{H}^{+}$exchanger NHE1 has previously been shown to be involved in fibroblast galvanotaxis, this was detected only when cells were exposed to supra-physiological EF strengths $(400 \mathrm{mV} / \mathrm{mm}$, Zhao et al., 2006). Under the physiological strength of the $100 \mathrm{mV} / \mathrm{mm}$ EF used in the current study, NHE1 does not mediate galvanotaxis in either normal human fibroblasts or keratinocytes. Our finding of ENaCmediated galvanotaxis in normal human keratinocytes implies a physiologic role for this mechanism in guiding directional migration of these cells in vivo, especially since it is welldocumented that wounding generates an endogenous EF to which the wound edge keratinocytes are immediately exposed. Thus, we propose that ENaC-mediated sensing of the EF plays a fundamental physiologic role in directing cell migration and contributing to wound repair. Additionally this work describes a novel role for $\mathrm{ENaC}$ in the epidermis, beyond the previously described function of modulating epidermal barrier formation (Charles et al., 2008).

\section{ENaC localization during galvanotaxis}

Because re-localization of some downstream mediators of the galvanotaxis response has been reported upon exposure of cells to an EF, we investigated whether there is a polarized localization of $\mathrm{ENaC}$ in the cells. During galvanotaxis, the directional response (cosine value) of keratinocytes starts increasing as soon as 15 minutes after exposure to the EF (Nishimura et al., 1996). Unlike the rapid polarization of EGFR and PI3K to the leading edge of galvanotactic keratinocytes (Fang et al., 1999; Zhao et al., 2006) or the Par-3 and Tiam-1 at the leading edge of migrating keratinocytes (Pegtel et al., 2007), ENaC does not polarize at the cathodal side of keratinocytes until a later time point (60 minutes) in the galvanotaxis response, suggesting that the polarization of $\mathrm{ENaC}$ does not initiate the directional migration of keratinocytes in response to the EF. It is possible that the late $\mathrm{ENaC}$ polarization we observe could be secondary to its known association with actin (Mazzochi et al., 2006), since actin reorganizes at the leading edge of migrating cells, in this case, the cathodal-facing edge of the cells. Similar results are found in the chemotactic Dictyostelium and neutrophils (Xiao et al., 1997; Servant et al., 1999). By time-lapsed imaging of the GFP-tagged chemoattractant receptor, the distribution of the chemoattractant receptors does not polarize at the leading edge when cells migrate and turn toward the attractant source, which suggests the polarization of the chemoattractant receptors is not required for the directional response of the cells.

\section{$\mathrm{ENaC}$ and lamellipodial protrusion}

We also examined if EFs induce the formation of dominant protrusions at the cathodal sides of exposed cells to polarize them, or if EF exposure can result in the asymmetric stabilization of protrusions thus promoting directional migration. The keratinocytes do not polarize immediately toward the cathode in an EF. Instead, kymographic analysis of the leading edge of galvanotactic cells shows that wild-type keratinocyte cells stabilize their cathodal protrusions, whereas ENaC-deficient cells cannot differentiate the cathodal and anodal sides of the cells in an EF in terms of lamellipodial protrusion. Lamellipodial protrusion depends on actin polymerization and depolymerization at the leading edge (Watanabe and Mitchison, 2002; Pollard and Borisy, 2003; Ponti et al., 2004). Asymmetric protrusion rate and distance between the cathodal side and anodal side could be an important mechanism to re-orient keratinocytes towards the cathode in the EF. At the present time there is not sufficient information to fully understand the mechanism by which $\mathrm{ENaC}$ may mediate lamellipodial dynamics. However, several studies suggest that $\mathrm{ENaC}$ associates with actin filaments and actin regulators. The c-terminus of $\alpha \mathrm{ENaC}$ has been shown to bind to F-actin in MDCK cells (Mazzochi et al., 2006) and the association is proposed to anchor $\mathrm{ENaC}$ at the plasma membrane. ENaC also binds to cortactin, an actin regulator to promote stable branching of F-actin (Ilatovskaya et al., 2011). Thus, we speculate that $\mathrm{ENaC}$ could also regulate actin dynamics via its binding to newly assembling actin filaments in the lamellipodium and thereby regulate lamellipodial protrusions. Further investigations will be required to elucidate these potential interactions.

\section{ENaC could be a cell sensor of an electric field}

We propose the overall hypothesis that $\mathrm{ENaC}$ functions as a proximal, cell membrane sensor of the EF. Several lines of evidence from the current study suggest that $\mathrm{ENaC}$ is a good candidate of the EF sensor on keratinocytes. First, ENaC is a membrane channel penetrating the well-insulated plasma membrane. The extracellular domain of $\mathrm{ENaC}$ is exposed to the medium where the EF is carried and the intracellular c-terminus is associated with actin (Mazzochi et al., 2006). Second, depleting $\mathrm{ENaC}$ from keratinocytes abolishes the galvanotaxis responses in keratinocytes ( $90 \%$ diminution in directedness). Inhibiting or deletion of other molecules known to be involved in the galvanotaxis response, such as PI3K- $\gamma / \mathrm{p} 110 \gamma$ and pTEN or $\beta 4$-integrin only result in a loss of $50 \%$ of the directionality (Pullar et al., 2006; Zhao et al., 2006). Partial loss of directionality when these signaling pathways are impaired suggests that parallel pathways converge to mediate galvanotaxis. However, the almost complete loss of directionality of $\mathrm{ENaC}$ knockout or knockdown cells implies that $\mathrm{ENaC}$ might be the most proximal signal of galvanotaxis signaling cascade initiating the directional response, and thus in the absence of $\mathrm{ENaC}$, none of the downstream signaling pathways can be activated to induce galvanotaxis. Also, unlike the other mediators noted above, $\mathrm{ENaC}$ is not involved in the migratory machinery. Knocking out ENaC from keratinocytes does not impair cell motility and the cells maintain lamellipodial extension, albeit in a non-directional, random migration pattern in 
the $\mathrm{EF}$, by an $\mathrm{ENaC}$-independent mechanism. $\mathrm{ENaC}$ in the wildtype cells may function to orient the persistent migration much like a steering molecule, which then directs the $\mathrm{ENaC}$-independent mechanism of locomotion. ENaC can also be opened by shear stress from stretch activation or fluid flow (Awayda et al., 1995; Carattino et al., 2004; Carattino et al., 2005; Wang et al., 2009; Fronius et al., 2010). Therefore, one may speculate that ENaC on the keratinocyte cell surface is susceptible to other mechanical forces and that voltage change generated by the $\mathrm{EF}$ may induce conformational changes in $\mathrm{ENaC}$, resulting in a galvanotaxis response.

In summary, we found that $\mathrm{ENaC}$ plays an important, and until now undiscovered, role in mediating the directional migration of keratinocyte in an EF. Here we propose a model for ENaC in mediating galvanotaxis. When an EF such as those endogenously generated in wounded skin is applied to keratinocytes, ENaC in the open state, located at the surface of migrating cells senses the field and promotes galvanotaxis by stabilizing the lamellipodial protrusions of the cathodal side and inhibiting the extensions at the anodal side. Galvanotactic cells then orient and turn slowly toward the cathode by means of their stable cathodal protrusions. Further studies are required to fully elucidate the mechanism by which $\mathrm{ENaC}$ mediates the protrusion process in response to an EF. Nevertheless, this novel function for the channel in the epidermis has broad implications for epithelial wound repair and the broad range of physiological responses of cells to endogenous EFs.

\section{Materials and Methods}

\section{Cell culture and $\alpha \mathrm{ENaC}$ knockout mice}

\section{Human and mouse keratinocytes}

Isolation of human foreskin keratinocytes was as described (Pullar and Isseroff, 2005) using a protocol approved by the UC Davis IRB. Neonatal human keratinocytes (NHK) were cultured in EpiLife medium with $1 \times$ HKGS and $1 \times$ Antibiotic-Antimycotic (Invitrogen, Chicago, IL). The generation of $\alpha \mathrm{ENaC}$ knockout mice was described in Hummler et al. (Hummler et al., 1996) Keratinocytes were isolated from newborn mice (mouse epithelial keratinocytes, MEK) using a protocol approved by the UC Davis IACUC. Briefly, 12- to 24-hourold pups were sterilized with Betadine/Triadine, and the skin was removed, incubated in dispase II solution $(10 \mathrm{mg} / \mathrm{ml}$, Roche Mol. Biochem, Indianapolis, IN) overnight at $4^{\circ} \mathrm{C}$. The epithelial layer was separated from dermis, soaked in $0.25 \%$ Trypsin-EDTA for 10 minutes at $37^{\circ} \mathrm{C}$, neutralized with $10 \%$ fetal bovine serum (FBS, Atlanta Biologicals, Lawrenceville, GA), gently agitated, filtered through $40 \mu \mathrm{m}$ cell strainers, and centrifuged. MEK were maintained in lowcalcium EpiLife $(20 \mu \mathrm{M} \mathrm{CaCl} 2)$ with $10 \mathrm{ng} / \mathrm{ml}$ mouse EGF (EMD Bioscience, Philadelphia, PA), $100 \mathrm{pM}$ cholera toxin (EMD Bioscience), $0.5 \%$ FBS and $1 \times$ Antibiotic-Antimycotic.

\section{H441 epithelial cells}

H441 and stably transfected sub-lines expressing EGFP (GFP7) or EGFP-tagged human $\alpha \mathrm{ENaC}(\alpha \mathrm{C} 3-3-\mathrm{GFP})$ were generated as described (Woollhead and Baines, 2006). H441 lines were cultured in RPMI 1640 custom medium (Invitrogen) containing l-glutamine $(2 \mathrm{mM})$, sodium pyruvate $(1 \mathrm{mM})$, insulin $(5 \mu \mathrm{g} / \mathrm{ml})$, transferrin $(5 \mu \mathrm{g} / \mathrm{ml})$, sodium selenite $(10 \mathrm{nM}), 10 \%$ FBS and antibiotics (penicillin/streptomycin). Cells transfected with the plasmids were maintained by Geneticin selection $(500 \mu \mathrm{g} / \mathrm{ml}$, Sigma-Aldrich, St. Louis, MO).

\section{NHE1-expressing fibroblasts}

NHE1-expressing fibroblasts PSN and E266I were kindly provided by Dr Diane Barber at UCSF. The fibroblasts carrying the wild-type NHE1 (PSN) and the E266I-NHE1 are derived from a NHE1-null parental cell line PS120 (lung fibroblasts from Chinese hamster). Expression level of the wild-type and mutant NHE1 in the cells are comparable and the $\mathrm{H}^{+}$efflux was examined to confirm loss of the ion transport function of E266I mutant protein (Denker et al., 2000). The PSN and E266I cells were cultured in DMEM (high-glucose, Invitrogen) with 5\% FBS, $1 \times$ Antibiotic-Antimycotic and $500 \mu \mathrm{g} / \mathrm{ml}$ Geneticin (Sigma-Aldrich). For the galvanotaxis assay, PSN and E266I cells were starved from FBS for 24 hours, seeded to the collagen I coated chambers for 12 hours and switched to $\mathrm{CO}_{2}$ independent medium (Invitrogen, supplied with $1 \times$ L-glutamine, 10\% FBS and $1 \times$ Antibiotic-Antimycotic) during the filming.

\section{Chemicals, siRNA and antibodies}

\section{Chemicals}

Phenamil (Sigma-Aldrich), Cariporide (a NHE1 specific inhibitor, gift from Dr Juergen Puenter, Sanofi-Aventis, Germany), S3969, (an ENaC activator, gift from Dr Bryan Moyer, Senomyx, CA) and DMSO (final dilution of 1:2500 to 1:5000) were added to NHK for 30 minutes before the electric field was applied.

\section{SiRNA}

Silencer ${ }^{\circledR}$ Pre-designed siRNA, $\mathrm{Cy}^{\mathrm{TM}} 3$ labeled (Cat\#AM16811, siRNA ID\# 6972 , human SCNN1A, 5' -/Cy3/GGUACCCGGAAAUUAAAGATT-3') against $\alpha$ ENaC and Silencer ${ }^{\circledR} \mathrm{Cy}^{\mathrm{TM}_{3}}$ labeled Negative Control \#1 siRNA (Cat\# 1621) were purchased from Ambion (Austin, TX). The siRNA was applied to NHK using the provided protocol and an additional treatment of the siRNA was followed 24 hours after the first treatment. Protein levels of $\mathrm{ENaC}$ and galvanotaxis were monitored 72 hours after the second siRNA treatment.

\section{ENaC inhibitory peptides}

Scrambled control peptide (QLHLLPPR) and ENaC inhibitory peptide (LPHPLQRL) (Carattino et al., 2006; Carattino et al., 2008) with acetylated and amidated ends were ordered (HPLC purified, purity $>90 \%$ ) from GenScript (Piscataway, NJ). NHKs were pre-treated with $20 \mu \mathrm{M}$ peptides for 1 hour before the galvanotaxis assay.

\section{Antibodies}

Anti- $\alpha$ ENaC aa627-643 rabbit antibodies (Calbiochem/EMD Chemicals, Gibbstown, NJ, 1:1000 for Western blotting and 1:200 for immunostaining), anti-rabbit secondary antibodies, HRP-linked (Cell signaling Tech., Danvers, MA, 1:1000 for western blotting) or Alexa Fluor 488 donkey anti-rabbit $\operatorname{IgG}\left(\mathrm{H}^{+} \mathrm{L}\right)$ secondary antibodies (Invitrogen, 1:500 for immunostaining) were used.

\section{Galvanotaxis}

Galvanotaxis was performed on passage $2-5$ cells from the primary cultures as described (Pullar et al., 2006). The galvanotaxis chambers were pre-coated with $100 \mu \mathrm{g} / \mathrm{ml}$ collagen I solution (Sigma-Aldrich) for cell migration. Cells were detached by $0.25 \%$ trypsin-EDTA (Invitrogen), neutralized with $10 \%$ FBS, centrifuged, seeded on the pre-coated galvanotaxis chambers at $6-8 \times 10^{4}$ cell $/ \mathrm{ml}$ until cells are attached (2-3 hours for human and mouse keratinocytes; 6 hours for H441, GFP7, and $\alpha \mathrm{C} 3-3-\mathrm{GFP}$, and 12 hours for PSN and E266I). Chemical treatments were applied to the cells for 30-60 minutes prior to the exposure of a $100 \mathrm{mV} / \mathrm{mm}$ DC electric field (EF), comparable to the physiological range at the wound field. Cell migration in the electric field was monitored for 60 minutes except in the experiments with NHE1 expressing fibroblasts PSN and E266I, where galvanotaxis was monitored for 3 hours in an electric field of $200 \mathrm{mV} / \mathrm{mm}$. In each treatment group, $80-120$ cells from 3-4 primary cell culture strains $(n=$ 3-4) or from three repeats of a cell line $(n=3)$ were tracked

\section{Western blotting and immunostaining}

Western blotting

NHK were rinsed with PBS and scraped from the culture plates with Costar Cell Lifters (Corning, Corning, NY) in 100-200 $\mu \mathrm{l}$ of lysis solution containing protease inhibitors: RIPA buffer (Sigma-Aldrich), $50 \mathrm{mM} \mathrm{NaF}$ (Sigma-Aldrich), $1 \mathrm{mM}$ Na3VO4 (Sigma-Aldrich), 1× Complete Protease Inhibitor Cocktail (Roche, Basel, Switzerland), $0.2 \mathrm{mg} / \mathrm{ml}$ PMSF (Sigma-Aldrich), and $0.5 \%$ Triton X-100 (Sigma-Aldrich). Cell lysates were spun at $12,000 \mathrm{rpm}$ at $4^{\circ} \mathrm{C}$ for 10 minutes and the supernatants were stored at $-20^{\circ} \mathrm{C}$. Protein concentration in the lysates was determined by Bio-Rad protein assay (Bio-Rad, Hercules, CA) and $30 \mu \mathrm{g}$ protein from each sample was loaded. SDS-PAGE and western blotting were performed with NuPAGE ${ }^{\circledR}$ Novex Gel Electrophoresis system (4-12\% gels, Invitrogen) and iBlot ${ }^{\circledR}$ Dry Blotting System (Invitrogen). The blot was then blocked with 5\% skim milk, incubated with primary antibodies for overnight at $4{ }^{\circ} \mathrm{C}$, washed and incubated with secondary antibodies for 2 hours at room temperature. ECL Western Blotting Detection Reagents (GE Healthcare, Little Chalfont, UK) was used to develop signals on X-ray films (Fujifilm, Tokyo, Japan). The protein bands on the blots were scanned and quantified by ImageJ program.

\section{Immunostaining}

After the exposure to the EF for different time periods, NHK attached to coverslips were fixed in $10 \%$ formaldehyde for 15 minutes. Cells were blocked by $4 \%$ BSA (BSA, Sigma-Aldrich), incubated with primary antibodies overnight at $4{ }^{\circ} \mathrm{C}$, washed, and incubated with secondary antibodies conjugated with fluorochromes for 2 hours at room temperature. The coverslips were mounted with ProLong ${ }^{\circledR}$ Gold antifade reagent with DAPI (Invitrogen)

\section{Image acquisition and analysis}

Image acquisition

Images were acquired on a Nikon TE-2000 microscope with a motorized stage, an environmental chamber to maintain at $37^{\circ} \mathrm{C}, 20 \times($ Nikon Plan Fluo, NA $=0.45$, for 
time-lapse imaging) and $60 \times$ (Nikon Plan Apo $\mathrm{VC}, \mathrm{NA}=1.40$ oil, for immunofluorescenct imaging) objectives, a Retiga EX camera (Qimaging, Canada) and Openlab and Volocity imaging software (PerkinElmer, Waltham, MA).

\section{Quantification of galvanotaxis}

For the fast moving cells, such as keratinocytes and H441 cells, time-lapse sequences of cell locomotion were obtained at 5-minute intervals for 1 hour. For slow moving cells, such as the NHE1 cells, the time-lapse movies were acquired at 15 -minute interval for 3 hours to allow the cells to move a distance of at least 40 $50 \mu \mathrm{m}$. Dividing cells in the movies were excluded from analysis since they were not motile until the end of mitosis. Cell tracking was performed with OpenLab software and the cell migration rate and directionality of galvanotaxis were calculated and shown as mean \pm s.e.m. In galvanotaxis, cell directionality was represented by the cosine value of trajectory of cell migration relative to the orientation of the EF. If the cells migrate directly toward the cathode or anode (galvanotaxis), the cosine value will be +1 (for cathodal migration) or -1 (for anodal migration). If cells migrate with random directionality, the average of net cosine will be close to zero. The final data were calculated and plotted with FileMaker Pro 8 Advanced (FileMaker, Santa Clara, CA) and Excel (Microsoft, Redmond, WA). The range of the keratinocyte migration speed is $1.0-2.0 \mu \mathrm{m} /$ minute and the range of the cosine values for keratinocyte galvanotaxis is $0.6-0.9$ depending on the cell strains from different donors.

\section{Quantification of immunostaining}

To quantify the immunostaining, fan-shaped or bipolar-shaped cells extending lamellipodia to both the cathodal and the anodal sides symmetrically in the EF were selected for comparison. Cathodal and anodal sides of the keratinocytes were defined by a line bisecting the cell relative to its orientation in the electric field. For the peripheral staining of $\alpha \mathrm{ENaC}$, the fluorescence intensity at the keratinocyte edge was measured and averaged.

\section{Kymograph analysis}

To track lamellipodial dynamics during galvanotaxis, fan-shaped cells facing perpendicularly to the axis of the electric field were filmed under a $60 \times$ oil objective. The change of the leading edge of the cells was monitored every 2 seconds for 10 minutes in the electric field. To analyze the images of the leading edges, the cell length was divided to 10 portions and 11 of the 1-pixel wide lines were drawn parallel to the migration direction at the cell periphery. Each cell is divided in half from the middle line to delineate the right, cathodal side and the left, anodal facing side. The kymographs were generated from the images of the stacked lines from the time-lapse movies with NIH ImageJ software (Fig. 5A). Protrusions are defined as extensions of the cell periphery and the retractions as shrinking of the cell periphery (Libotte et al., 2001; Borm. et al., 2005; Taboubi et al., 2007). The distance and slope (the speed) of protrusions and retractions in each kymograph were calculated with the kymograph tools in ImageJ. To perform the statistical analysis, the kymograph data from the anodal side were compared to the counterpart from the cathodal side. For example, the kymograph data from line 1 is compared with line 9 , line 2 with line 8 and line 3 with line 7 etc. Nine to thirteen cells were analyzed in each group.

\section{Statistics}

All the experiments were repeated 3-4 times and the bar graphs compared using the Student's $t$-test in Excel. If the $P$ value is smaller than 0.05 , the results between the two treatment groups are considered significantly different.

\section{Acknowledgements}

We thank Dr Juergen Puenter (Sanofi-Aventis, Germany) for providing Cariporide, Dr Bryan Moyer (Senomyx, CA) for providing S3969, and Dr Diane Barber at UCSF for the NHE1 expressing fibroblasts. We also thank Dr Rich Nuccitelli for facilitating the collaborative effort, and Dr Alex Mogilner at UC Davis for helpful discussions on the manuscript.

\section{Author contributions}

H.-y.Y. designed and performed the experiments, analysed the data, and wrote the manuscript; R.-P.C. and E.H. generated and provided the $\mathrm{aENaC} \mathrm{KO}$ mice and cells, and contributed to the discussion and revision of the manuscript; D.L.B. generated and provided the H441 $\mathrm{ENaC}$ expressing cell lines, and contributed to the discussion and revision of the manuscript; R.R.I. contributed to the designs and discussions of the experiments and revised the manuscript.

\section{Funding}

H.-y.Y and R.R.I. were supported by the National Institute of Arthritis and Musculoskeletal and Skin Diseases, National Institutes of Health (NIH) [grant number R01AR044518]. This research received no other funding for R.P.C., E.H. and D.L.B. Deposited in PMC for release after 12 months.

Supplementary material available online at

http://jcs.biologists.org/lookup/suppl/doi:10.1242/jcs.113225/-/DC1

\section{References}

Alvarez de la Rosa, D., Canessa, C. M., Fyfe, G. K. and Zhang, P. (2000). Structure and regulation of amiloride-sensitive sodium channels. Annu. Rev. Physiol. 62, 573594.

Andrew, N. and Insall, R. H. (2007). Chemotaxis in shallow gradients is mediated independently of PtdIns 3-kinase by biased choices between random protrusions. Nat. Cell Biol. 9, 193-200.

Awayda, M. S., Ismailov, I. I., Berdiev, B. K. and Benos, D. J. (1995). A cloned renal epithelial $\mathrm{Na}+$ channel protein displays stretch activation in planar lipid bilayers. $\mathrm{Am}$. J. Physiol. 268, C1450-C1459.

Awayda, M. S., Tousson, A. and Benos, D. J. (1997). Regulation of a cloned epithelial $\mathrm{Na}+$ channel by its beta- and gamma-subunits. Am. J. Physiol. 273, C1889-C1899.

Barker, A. T., Jaffe, L. F. and Vanable, J. W. Jr. (1982). The glabrous epidermis of cavies contains a powerful battery. Am. J. Physiol. 242, R358-R366.

Benos, D. J., Awayda, M. S., Berdiev, B. K., Bradford, A. L., Fuller, C. M., Senyk, O. and Ismailov, I. I. (1996). Diversity and regulation of amiloride-sensitive $\mathrm{Na}+$ channels. Kidney Int. 49, 1632-1637.

Borgens, R. B., Vanable, J. W., Jr and Jaffe, L. F. (1977). Bioelectricity and regeneration: large currents leave the stumps of regenerating newt limbs. Proc. Natl. Acad. Sci. USA 74, 4528-4532.

Borm, B., Requardt, R. P., Herzog, V. and Kirfel, G. (2005). Membrane ruffles in cell migration: indicators of inefficient lamellipodia adhesion and compartments of actin filament reorganization. Exp. Cell Res. 302, 83-95.

Brouard, M., Casado, M., Djelidi, S., Barrandon, Y. and Farman, N. (1999). Epithelial sodium channel in human epidermal keratinocytes: expression of its subunits and relation to sodium transport and differentiation. J. Cell Sci. 112, 33433352

Burr, H. S. (1941). Field Properties of the Developing Frog's Egg. Proc. Natl. Acad. Sci. USA 27, 276-281.

Carattino, M. D., Sheng, S. and Kleyman, T. R. (2004). Epithelial Na+ channels are activated by laminar shear stress. J. Biol. Chem. 279, 4120-4126.

Carattino, M. D., Sheng, S. and Kleyman, T. R. (2005). Mutations in the pore region modify epithelial sodium channel gating by shear stress. J. Biol. Chem. 280, 43934401

Carattino, M. D., Sheng, S., Bruns, J. B., Pilewski, J. M., Hughey, R. P. and Kleyman, T. R. (2006). The epithelial Na+ channel is inhibited by a peptide derived from proteolytic processing of its alpha subunit. J. Biol. Chem. 281, 18901-18907.

Carattino, M. D., Passero, C. J., Steren, C. A., Maarouf, A. B., Pilewski, J. M., Myerburg, M. M., Hughey, R. P. and Kleyman, T. R. (2008). Defining an inhibitory domain in the alpha-subunit of the epithelial sodium channel. Am. J. Physiol. Renal Physiol. 294, F47-F52.

Chang, S. S., Grunder, S., Hanukoglu, A., Rösler, A., Mathew, P. M., Hanukoglu, I., Schild, L., Lu, Y., Shimkets, R. A., Nelson-Williams, C. et al. (1996). Mutations in subunits of the epithelial sodium channel cause salt wasting with hyperkalaemic acidosis, pseudohypoaldosteronism type 1. Nat. Genet. 12, 248-253.

Charles, R. P., Guitard, M., Leyvraz, C., Breiden, B., Haftek, M., Haftek-Terreau, Z., Stehle, J. C., Sandhoff, K. and Hummler, E. (2008). Postnatal requirement of the epithelial sodium channel for maintenance of epidermal barrier function. J. Biol. Chem. 283, 2622-2630.

Chifflet, S., Hernández, J. A. and Grasso, S. (2005). A possible role for membrane depolarization in epithelial wound healing. Am. J. Physiol. Cell Physiol. 288, C1420C1430.

Del Mónaco, S. M., Marino, G. I., Assef, Y. A., Damiano, A. E. and Kotsias, B. A. (2009). Cell migration in BeWo cells and the role of epithelial sodium channels. J. Membr. Biol. 232, 1-13.

Denda, M., Hosoi, J. and Asida, Y. (2000). Visual imaging of ion distribution in human epidermis. Biochem. Biophys. Res. Commun. 272, 134-137.

Denker, S. P., Huang, D. C., Orlowski, J., Furthmayr, H. and Barber, D. L. (2000). Direct binding of the $\mathrm{Na}-\mathrm{H}$ exchanger NHE1 to ERM proteins regulates the cortical cytoskeleton and cell shape independently of $\mathrm{H}(+)$ translocation. Mol. Cell 6, 14251436

Fang, K. S., Farboud, B., Nuccitelli, R. and Isseroff, R. R. (1998). Migration of human keratinocytes in electric fields requires growth factors and extracellular calcium. J. Invest. Dermatol. 111, 751-756.

Fang, K. S., Ionides, E., Oster, G., Nuccitelli, R. and Isseroff, R. R. (1999). Epidermal growth factor receptor relocalization and kinase activity are necessary for directional migration of keratinocytes in DC electric fields. J. Cell Sci. 112, 1967-1978.

Farboud, B., Nuccitelli, R., Schwab, I. R. and Isseroff, R. R. (2000). DC electric fields induce rapid directional migration in cultured human corneal epithelial cells. Exp. Eye Res. 70, 667-673. 
Foulds, I. S. and Barker, A. T. (1983). Human skin battery potentials and their possible role in wound healing. Br. J. Dermatol. 109, 515-522.

Frantz, C., Karydis, A., Nalbant, P., Hahn, K. M. and Barber, D. L. (2007). Positive feedback between $\mathrm{Cdc} 42$ activity and $\mathrm{H}+$ efflux by the Na-H exchanger NHE1 for polarity of migrating cells. J. Cell Biol. 179, 403-410.

Frelin, C., Barbry, P., Vigne, P., Chassande, O., Cragoe, E. J., Jr and Lazdunski, M. (1988). Amiloride and its analogs as tools to inhibit $\mathrm{Na}+$ transport via the $\mathrm{Na}+$ channel, the $\mathrm{Na}+/ \mathrm{H}+$ antiport and the $\mathrm{Na}+/ \mathrm{Ca} 2+$ exchanger. Biochimie 70, 1285-1290

Fronius, M., Bogdan, R., Althaus, M., Morty, R. E. and Clauss, W. G. (2010) Epithelial $\mathrm{Na}+$ channels derived from human lung are activated by shear force. Respir. Physiol. Neurobiol. 170, 113-119.

Garty, H. and Palmer, L. G. (1997). Epithelial sodium channels: function, structure, and regulation. Physiol. Rev. 77, 359-396.

Grifoni, S. C., Gannon, K. P., Stec, D. E. and Drummond, H. A. (2006). ENaC proteins contribute to VSMC migration. Am. J. Physiol. Heart Circ. Physiol. 291, H3076-H3086

Grifoni, S. C., Jernigan, N. L., Hamilton, G. and Drummond, H. A. (2008). ASIC proteins regulate smooth muscle cell migration. Microvasc. Res. 75, 202-210.

Hachem, J. P., Behne, M., Aronchik, I., Demerjian, M., Feingold, K. R., Elias, P. M. and Mauro, T. M. (2005). Extracellular pH Controls NHE1 expression in epidermis and keratinocytes: implications for barrier repair. J. Invest. Dermatol. 125, 790-797.

Hirsh, A. J., Sabater, J. R., Zamurs, A., Smith, R. T., Paradiso, A. M., Hopkins, S., Abraham, W. M. and Boucher, R. C. (2004). Evaluation of second generation amiloride analogs as therapy for cystic fibrosis lung disease. J. Pharmacol. Exp. Ther 311, 929-938.

Hummler, E., Barker, P., Gatzy, J., Beermann, F., Verdumo, C., Schmidt, A., Boucher, R. and Rossier, B. C. (1996). Early death due to defective neonatal lung liquid clearance in alpha-ENaC-deficient mice. Nat. Genet. 12, 325-328.

Ilatovskaya, D. V., Pavlov, T. S., Levchenko, V., Negulyaev, Y. A. and Staruschenko, A. (2011). Cortical actin binding protein cortactin mediates ENaC activity via Arp2/3 complex. FASEB J. 25, 2688-2699.

Kratz, G. (1998). Modeling of wound healing processes in human skin using tissue culture. Microsc. Res. Tech. 42, 345-350.

Leinonen, P. T., Hägg, P. M., Peltonen, S., Jouhilahti, E.-M., Melkko, J., Korkiamäki, T., Oikarinen, A. and Peltonen, J. (2009). Reevaluation of the normal epidermal calcium gradient, and analysis of calcium levels and ATP receptors in Hailey-Hailey and Darier epidermis. J. Invest. Dermatol. 129, 1379-1387.

Libotte, T., Kaiser, H. W., Alt, W. and Bretschneider, T. (2001). Polarity, protrusionretraction dynamics and their interplay during keratinocyte cell migration. Exp. Cell Res. 270, 129-137.

Lu, H. and Rollman, O. (2004). Fluorescence imaging of reepithelialization from skin explant cultures on acellular dermis. Wound Repair Regen. 12, 575-586.

Lu, M., Echeverri, F., Kalabat, D., Laita, B., Dahan, D. S., Smith, R. D., Xu, H., Staszewski, L., Yamamoto, J., Ling, J. et al. (2008). Small molecule activator of the human epithelial sodium channel. J. Biol. Chem. 283, 11981-11994.

Martín, J. M., Calduch, L., Monteagudo, C., Alonso, V., García, L. and Jordá, E. (2005). Clinico-pathological analysis of the cutaneous lesions of a patient with type I pseudohypoaldosteronism. J. Eur. Acad. Dermatol. Venereol. 19, 377-379.

Mauro, T., Guitard, M., Behne, M., Oda, Y., Crumrine, D., Komuves, L., Rassner, U., Elias, P. M. and Hummler, E. (2002). The ENaC channel is required for normal epidermal differentiation. J. Invest. Dermatol. 118, 589-594.

Mazzochi, C., Bubien, J. K., Smith, P. R. and Benos, D. J. (2006). The carboxyl terminus of the alpha-subunit of the amiloride-sensitive epithelial sodium channe binds to F-actin. J. Biol. Chem. 281, 6528-6538.

McCaig, C. D., Rajnicek, A. M., Song, B., Zhao, M.; MCCAI (2005). Controlling cell behavior electrically: current views and future potential. Physiol. Rev. 85, 943-978.

McDonald, F. J., Snyder, P. M., McCray, P. B., Jr and Welsh, M. J. (1994). Cloning, expression, and tissue distribution of a human amiloride-sensitive $\mathrm{Na}+$ channel. Am. J. Physiol. 266, L728-L734.

McDonald, F. J., Price, M. P., Snyder, P. M. and Welsh, M. J. (1995). Cloning and expression of the beta- and gamma-subunits of the human epithelial sodium channel. Am. J. Physiol. 268, C1157-C1163.

Mukerjee, E. V., Isseroff, R. R., Nuccitelli, R., Collins, S. D. and Smith, R. L. (2006). Microneedle array for measuring wound generated electric fields. Conf. Proc. IEEE Eng. Med. Biol. Soc. 1, 4326-4328.

Nishimura, K. Y., Isseroff, R. R. and Nuccitelli, R. (1996). Human keratinocytes migrate to the negative pole in direct current electric fields comparable to those measured in mammalian wounds. J. Cell Sci. 109, 199-207.

Nuccitelli, R., Nuccitelli, P., Ramlatchan, S., Sanger, R. and Smith, P. J. (2008). Imaging the electric field associated with mouse and human skin wounds. Wound Repair Regen. 16, 432-441.

Ojingwa, J. C. and Isseroff, R. R. (2003). Electrical stimulation of wound healing. J. Invest. Dermatol. 121, 1-12.

Pegtel, D. M., Ellenbroek, S. I., Mertens, A. E., van der Kammen, R. A., de Rooij, J. and Collard, J. G. (2007). The Par-Tiam1 complex controls persistent migration by stabilizing microtubule-dependent front-rear polarity. Curr. Biol. 17, 1623-1634.
Pollard, T. D. and Borisy, G. G. (2003). Cellular motility driven by assembly and disassembly of actin filaments. Cell 112, 453-465.

Ponti, A., Machacek, M., Gupton, S. L., Waterman-Storer, C. M. and Danuser, G. (2004). Two distinct actin networks drive the protrusion of migrating cells. Science 305, 1782-1786

Pullar, C. E. and Isseroff, R. R. (2005). Cyclic AMP mediates keratinocyte directional migration in an electric field. J. Cell Sci. 118, 2023-2034.

Pullar, C. E., Baier, B. S., Kariya, Y., Russell, A. J., Horst, B. A., Marinkovich, M. P. and Isseroff, R. R. (2006). beta4 integrin and epidermal growth factor coordinately regulate electric field-mediated directional migration via Rac1. Mol. Biol. Cell 17, 4925-4935.

Reid, B., Nuccitelli, R. and Zhao, M. (2007). Non-invasive measurement of bioelectric currents with a vibrating probe. Nat. Protoc. 2, 661-669.

Scholz, W., Albus, U., Counillon, L., Gögelein, H., Lang, H.-J., Linz, W., Weichert, A. and Schölkens, B. A. (1995). Protective effects of HOE642, a selective sodiumhydrogen exchange subtype 1 inhibitor, on cardiac ischaemia and reperfusion. Cardiovasc. Res. 29, 260-268.

Servant, G., Weiner, O. D., Neptune, E. R., Sedat, J. W. and Bourne, H. R. (1999). Dynamics of a chemoattractant receptor in living neutrophils during chemotaxis. Mol. Biol. Cell 10, 1163-1178.

Sheridan, D. M., Isseroff, R. R. and Nuccitelli, R. (1996). Imposition of a physiologic DC electric field alters the migratory response of human keratinocytes on extracellular matrix molecules. J. Invest. Dermatol. 106, 642-646.

Stock, C., Gassner, B., Hauck, C. R., Arnold, H., Mally, S., Eble, J. A., Dieterich, P. and Schwab, A. (2005). Migration of human melanoma cells depends on extracellular $\mathrm{pH}$ and $\mathrm{Na}+/ \mathrm{H}+$ exchange. J. Physiol. 567, 225-238.

Strautnieks, S. S., Thompson, R. J., Hanukoglu, A., Dillon, M. J., Hanukoglu, I., Kuhnle, U., Seckl, J., Gardiner, R. M. and Chung, E. (1996). Localisation of pseudohypoaldosteronism genes to chromosome 16p12.2-13.11 and 12p13.1-pter by homozygosity mapping. Hum. Mol. Genet. 5, 293-299.

Taboubi, S., Milanini, J., Delamarre, E., Parat, F., Garrouste, F., Pommier, G., Takasaki, J., Hubaud, J. C., Kovacic, H. and Lehmann, M. (2007). G alpha(q/11)coupled P2Y2 nucleotide receptor inhibits human keratinocyte spreading and migration. FASEB J. 21, 4047-4058

Trollinger, D. R., Isseroff, R. R. and Nuccitelli, R. (2002). Calcium channel blockers inhibit galvanotaxis in human keratinocytes. J. Cell. Physiol. 193, 1-9.

Urbatsch, A. and Paller, A. S. (2002). Pustular miliaria rubra: a specific cutaneous finding of type I pseudohypoaldosteronism. Pediatr. Dermatol. 19, 317-319.

Voilley, N., Lingueglia, E., Champigny, G., Mattéi, M. G., Waldmann, R., Lazdunski, M. and Barbry, P. (1994). The lung amiloride-sensitive Na+ channel: biophysical properties, pharmacology, ontogenesis, and molecular cloning. Proc. Natl. Acad. Sci. USA 91, 247-251.

Voilley, N., Bassilana, F., Mignon, C., Merscher, S., Mattéi, M. G., Carle, G. F., Lazdunski, M. and Barbry, P. (1995). Cloning, chromosomal localization, and physical linkage of the beta and gamma subunits (SCNN1B and SCNN1G) of the human epithelial amiloride-sensitive sodium channel. Genomics 28, 560-565.

Wang, S., Meng, F., Mohan, S., Champaneri, B. and Gu, Y. (2009). Functional ENaC channels expressed in endothelial cells: a new candidate for mediating shear force. Microcirculation 16, 276-287.

Watanabe, N. and Mitchison, T. J. (2002). Single-molecule speckle analysis of actin filament turnover in lamellipodia. Science 295, 1083-1086.

Woollhead, A. M. and Baines, D. L. (2006). Forskolin-induced cell shrinkage and apical translocation of functional enhanced green fluorescent protein-human alphaENaC in $\mathrm{H} 441$ lung epithelial cell monolayers. J. Biol. Chem. 281, 5158-5168.

Xiao, Z., Zhang, N., Murphy, D. B. and Devreotes, P. N. (1997). Dynamic distribution of chemoattractant receptors in living cells during chemotaxis and persistent stimulation. J. Cell Biol. 139, 365-374.

Zhao, M., Agius-Fernandez, A., Forrester, J. V. and McCaig, C. D. (1996) Orientation and directed migration of cultured corneal epithelial cells in small electric fields are serum dependent. J. Cell Sci. 109, 1405-1414.

Zhao, M., McCaig, C. D., Agius-Fernandez, A., Forrester, J. V. and Araki-Sasaki, K. (1997). Human corneal epithelial cells reorient and migrate cathodally in a small applied electric field. Curr. Eye Res. 16, 973-984.

Zhao, M., Dick, A., Forrester, J. V. and McCaig, C. D. (1999). Electric field-directed cell motility involves up-regulated expression and asymmetric redistribution of the epidermal growth factor receptors and is enhanced by fibronectin and laminin. $\mathrm{Mol}$. Biol. Cell 10, 1259-1276.

Zhao, M., Pu, J., Forrester, J. V. and McCaig, C. D. (2002). Membrane lipids, EGF receptors, and intracellular signals colocalize and are polarized in epithelial cells moving directionally in a physiological electric field. FASEB J. 16, 857-859.

Zhao, M., Song, B., Pu, J., Wada, T., Reid, B., Tai, G., Wang, F., Guo, A., Walczysko, P., Gu, Y. et al. (2006). Electrical signals control wound healing through phosphatidylinositol-3-OH kinase-gamma and PTEN. Nature 442, 457-460. 